\title{
$-11+14$ \\ BIOMATERIALS AND \\ BIOACTIVE MOLECULES TO \\ DRIVE DIFFERENTIATION IN \\ STRIATED MUSCLE TISSUE \\ ENGINEERING
}

\section{EDITED BY: Valentina Di Felice, Giancarlo Forte and Dario Coletti PUBLISHED IN: Frontiers in Physiology}

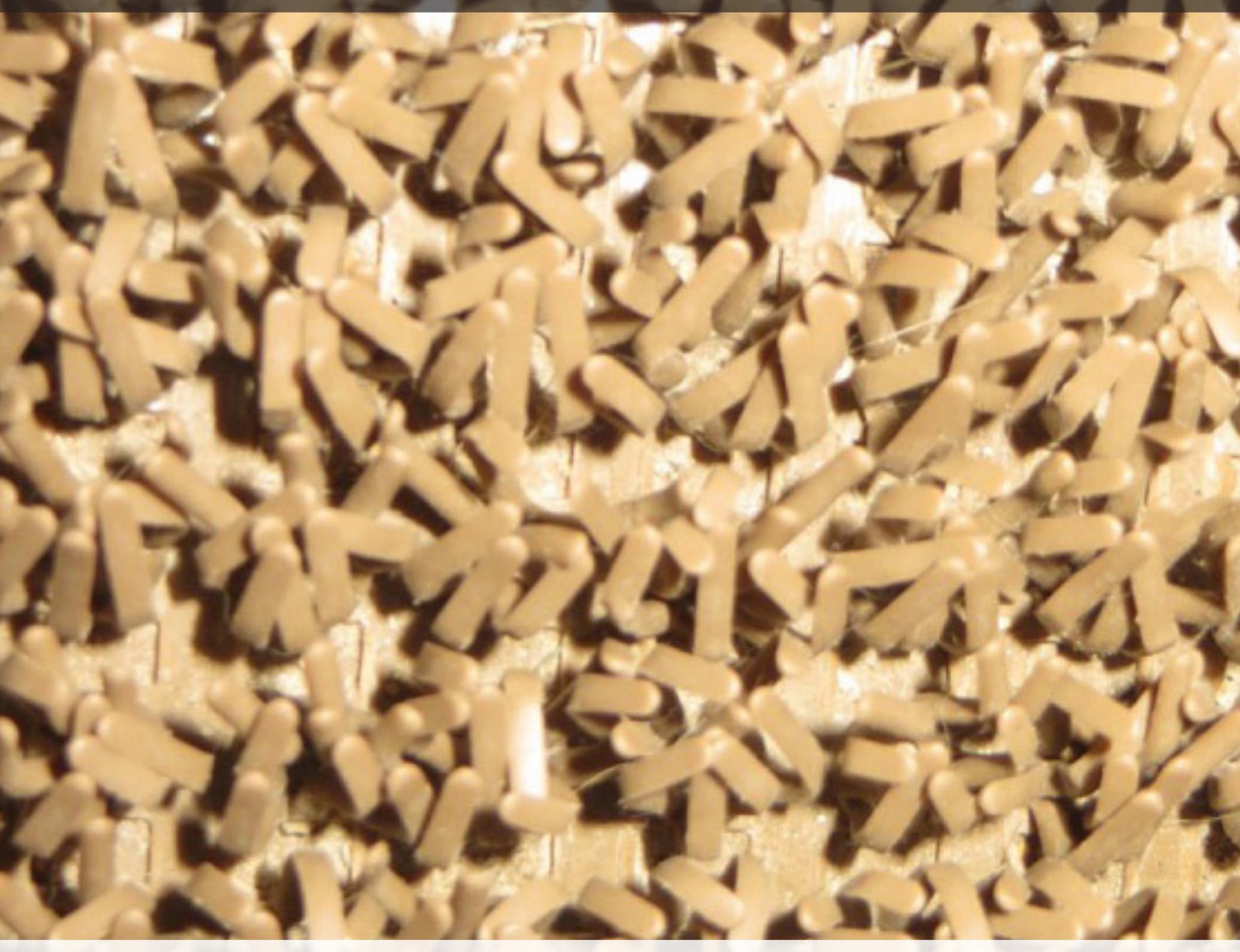




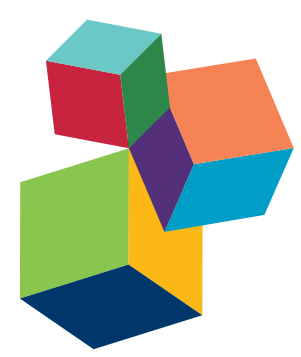

Frontiers Copyright Statement

(c) Copyright 2007-2016 Frontiers Media SA. All rights reserved.

All content included on this site, such as text, graphics, logos, button icons, images, video/audio clips, downloads, data compilations and software, is the property of or is licensed to Frontiers Media SA

("Frontiers") or its licensees and/or subcontractors. The copyright in the text of individual articles is the property of their respective authors, subject to a license granted to Frontiers.

The compilation of articles constituting this e-book, wherever published, as well as the compilation of all other content on this site, is the exclusive property of Frontiers. For the conditions for downloading and copying of e-books from Frontiers' website, please see the Terms for Website Use. If purchasing Frontiers e-books from other websites or sources, the conditions of the website concerned apply.

Images and graphics not forming part of user-contributed materials may not be downloaded or copied without permission.

Individual articles may be downloaded and reproduced in accordance with the principles of the CC-BY licence subject to any copyright or other notices. They may not be re-sold as an e-book.

As author or other contributor you grant a $C C-B Y$ licence to others to reproduce your articles, including any graphics and third-party materials supplied by you, in accordance with the Conditions for Website Use and subject to any copyright notices which you include in connection with your articles and materials.

All copyright, and all rights therein, are protected by national and international copyright laws.

The above represents a summary only. For the full conditions see the Conditions for Authors and the Conditions for Website Use.

ISSN 1664-8714 ISBN 978-2-88919-841-2

DOI 10.3389/978-2-88919-841-2

\section{About Frontiers}

Frontiers is more than just an open-access publisher of scholarly articles: it is a pioneering approach to the world of academia, radically improving the way scholarly research is managed. The grand vision of Frontiers is a world where all people have an equal opportunity to seek, share and generate knowledge. Frontiers provides immediate and permanent online open access to all its publications, but this alone is not enough to realize our grand goals.

\section{Frontiers Journal Series}

The Frontiers Journal Series is a multi-tier and interdisciplinary set of open-access, online journals, promising a paradigm shift from the current review, selection and dissemination processes in academic publishing. All Frontiers journals are driven by researchers for researchers; therefore, they constitute a service to the scholarly community. At the same time, the Frontiers Journal Series operates on a revolutionary invention, the tiered publishing system, initially addressing specific communities of scholars, and gradually climbing up to broader public understanding, thus serving the interests of the lay society, too.

\section{Dedication to Quality}

Each Frontiers article is a landmark of the highest quality, thanks to genuinely collaborative interactions between authors and review editors, who include some of the world's best academicians. Research must be certified by peers before entering a stream of knowledge that may eventually reach the public - and shape society; therefore, Frontiers only applies the most rigorous and unbiased reviews.

Frontiers revolutionizes research publishing by freely delivering the most outstanding research, evaluated with no bias from both the academic and social point of view. By applying the most advanced information technologies, Frontiers is catapulting scholarly publishing into a new generation.

\section{What are Frontiers Research Topics?}

Frontiers Research Topics are very popular trademarks of the Frontiers Journals Series: they are collections of at least ten articles, all centered on a particular subject. With their unique mix of varied contributions from Original Research to Review Articles, Frontiers Research Topics unify the most influential researchers, the latest key findings and historical advances in a hot research area! Find out more on how to host your own Frontiers Research Topic or contribute to one as an author by contacting the Frontiers Editorial Office: researchtopics@frontiersin.org 


\title{
BIOMATERIALS AND BIOACTIVE MOLECULES TO DRIVE DIFFERENTIATION IN STRIATED MUSCLE TISSUE ENGINEERING
}

\author{
Topic Editors: \\ Valentina Di Felice, University of Palermo, Italy \\ Giancarlo Forte, St. Anne's University Hospital Brno, Czech Republic \\ Dario Coletti, Pierre and Marie Curie University, France
}

Tissue engineering is an innovative, multidisciplinary approach which combines (bio)materials, cells and growth factors with the aim to obtain neo-organogenesis to repair or replenish damaged tissues and organs. The generation of engineered tissues and organs (e. g. skin and bladder) has entered into the clinical practice in response to the chronic lack of organ donors. In particular, for the skeletal and cardiac muscles the translational potential of tissue engineering approaches has clearly been shown, even though the construction of this tissue lags behind others given the hierarchical, highly organized architecture of striated muscles.

Cardiovascular disease is the leading cause of death in the developed world, where the yearly incidence of Acute MI (AMI) is approx 2 million cases in Europe. Recovery from AMI and reperfusion is still less than ideal. Stem cell therapy may represent a valid treatment. However, delivery of stem cells alone to infarcted myocardium provides no structural support while the myocardium heals, and the injected stem cells do not properly integrate into the myocardium because they are not subjected to the mechanical forces that are known to drive myocardial cellular physiology.

On the other hand, there are many clinical cases where the loss of skeletal muscle due to a traumatic injury, an aggressive tumour or prolonged denervation may be cured by the regeneration of this tissue.

In vivo, stem or progenitor cells are sheltered in a specialized microenvironment (niche), which regulates their survival, proliferation and differentiation. The goal of this research topic is to highlight the available knowledge on biomaterials and bioactive molecules or a combination of them, which can be used successfully to differentiate stem or progenitor cells into beating cardiomyocytes or organized skeletal muscle in vivo. Innovations compared to the on-going trials may be: 1) the successful delivery of stem cells using sutural scaffolds instead of intracoronary or intramuscular injections; 2) protocols to use a limited number of autologous or allogeneic stem 
cells; 3) methods to drive their differentiation by modifying the chemical-physical properties of scaffolds or biomaterials, incorporating small molecules (i.e. miRNA) or growth factors; 4) methods to tailor the scaffolds to the elastic properties of the muscle; 5) studies which suggest how to realize scaffolds that optimize tissue functional integration, through the combination of the most up-to-date manufacturing technologies and use of bio-polymers with customized degradation properties.

Citation: Di Felice, V., Forte, G., Coletti, D., eds. (2016). Biomaterials and Bioactive Molecules to Drive Differentiation in Striated Muscle Tissue Engineering. Lausanne: Frontiers Media.

doi: $10.3389 / 978-2-88919-841-2$ 


\title{
Barbara Perniconi ${ }^{1,2+}$, Dario Coletti ${ }^{1,3,4 t}$, Paola Aulino ${ }^{2,3,4}$, Alessandra Costa ${ }^{3,4,5}$, Paola Aprile ${ }^{5,6}$, Luigi Santacroce ${ }^{7}$, Ernesto Chiaravalloti ${ }^{2}$, Laura Coquelin ${ }^{8}$, Nathalie Chevallier ${ }^{8}$, Laura Teodori ${ }^{5}$, Sergio Adamo ${ }^{3,4 *}$, Massimo Marrelli ${ }^{2,9 \dagger}$ and Marco Tatullo ${ }^{2,9 \dagger}$
}

\author{
1 Department of Biological Adaptation and Aging (B2A) UMR 8256 CNRS - ERL U1164 INSERM, Sorbonne Universités, UPMC University Paris 06, Paris, France \\ ${ }^{2}$ Maxillofacial Unit, Calabrodental Clinic, Crotone, Italy \\ ${ }^{3}$ AHFOS Department - Section of Histology and Medical Embryology, Sapienza University of Rome, Rome, Italy \\ ${ }^{4}$ Interuniversitary Institute of Miology (IIM), Rome, Italy \\ ${ }^{5}$ UTAPRAD-DIM, ENEA, Frascati, Italy \\ ${ }^{6}$ Tor Vergata University of Rome, Rome, Italy \\ 7 JSGEM Department - Section of Taranto, University of Bari, Taranto, Italy \\ ${ }^{8}$ Unite d'Ingénierie et de Therapie Cellulaire, Etablissement Français du Sang lle de France, Université Paris-Est Créteil, Créteil, France \\ ${ }^{9}$ Regenerative Medicine Section, Tecnologica Research Institute, Crotone, Italy
}

\section{Edited by:}

Valentina Di Felice, University of

Palermo, Italy

\section{Reviewed by:}

Tracy Criswell, Wake Forest

University, USA

Fuchun Yang, The First Affiliated Hospital of The Guangxi Medical

University, China

\section{*Correspondence:}

Sergio Adamo, AHFOS Department - Section of Histology and Medical Embryology, Via Scarpa 16, 00161 Rome, Italy

e-mail:sergio.adamo@uniroma1.it

these authors have contributed equally to this work.
The extracellular matrix (ECM) of decellularized organs possesses the characteristics of the ideal tissue-engineering scaffold (i.e., histocompatibility, porosity, degradability, non-toxicity). We previously observed that the muscle acellular scaffold (MAS) is a pro-myogenic environment in vivo. In order to determine whether MAS, which is basically muscle ECM, behaves as a myogenic environment, regardless of its location, we analyzed MAS interaction with both muscle and non-muscle cells and tissues, to assess the effects of MAS on cell differentiation. Bone morphogenetic protein treatment of $\mathrm{C} 2 \mathrm{C} 12$ cells cultured within MAS induced osteogenic differentiation in vitro, thus suggesting that MAS does not irreversibly commit cells to myogenesis. In vivo MAS supported formation of nascent muscle fibers when replacing a muscle (orthotopic position). However, heterotopically grafted MAS did not give rise to muscle fibers when transplanted within the renal capsule. Also, no muscle formation was observed when MAS was transplanted under the xiphoid process, in spite of the abundant presence of cells migrating along the laminin-based MAS structure. Taken together, our results suggest that MAS itself is not sufficient to induce myogenic differentiation. It is likely that the pro-myogenic environment of MAS is not strictly related to the intrinsic properties of the muscle scaffold (e.g., specific muscle ECM proteins). Indeed, it is more likely that myogenic stem cells colonizing MAS recognize a muscle environment that ultimately allows terminal myogenic differentiation. In conclusion, MAS may represent a suitable environment for muscle and non-muscle 3D constructs characterized by a highly organized structure whose relative stability promotes integration with the surrounding tissues. Our work highlights the plasticity of MAS, suggesting that it may be possible to consider MAS for a wider range of tissue engineering applications than the mere replacement of volumetric muscle loss.

Keywords: extracellular matrix, niche, osteogenic differentiation, myogenic differentiation, tissue engineering, regenerative medicine

\section{INTRODUCTION}

A niche is composed of elements that surround stem cells: tissue specific cells, extracellular matrix and local growth factors (Yin et al., 2013). These elements determine the local microenvironment that supports the maintenance of stem cell identity and regulates the function of stem cells (Kuang et al., 2008). In addition, the niche supports stem cells and controls their self-renewal in vivo (Spradling et al., 2001) by modulating the asymmetric cell division insomuch as it ensures stem cell renewal and production of a sufficient number of committed daughter cells for tissue homeostasis and repair (Kuang et al., 2008). It is worth bearing in mind that the local microenvironment affects not only stem cell behavior (particularly the stem cell specific auto-renewal feature) but also the differentiation potential and cell division of committed daughter cells deriving from stem cell asymmetrical division. Indeed, a fibroblast-specific niche has been described for cell culture purposes (Sivan et al., 2014), while the bone marrow niche that regulates hematopoietic stem cells is also reported to be necessary for B-cell commitment (Adler et al., 2014). Future challenges involved in the recreation of cell niches as platforms 


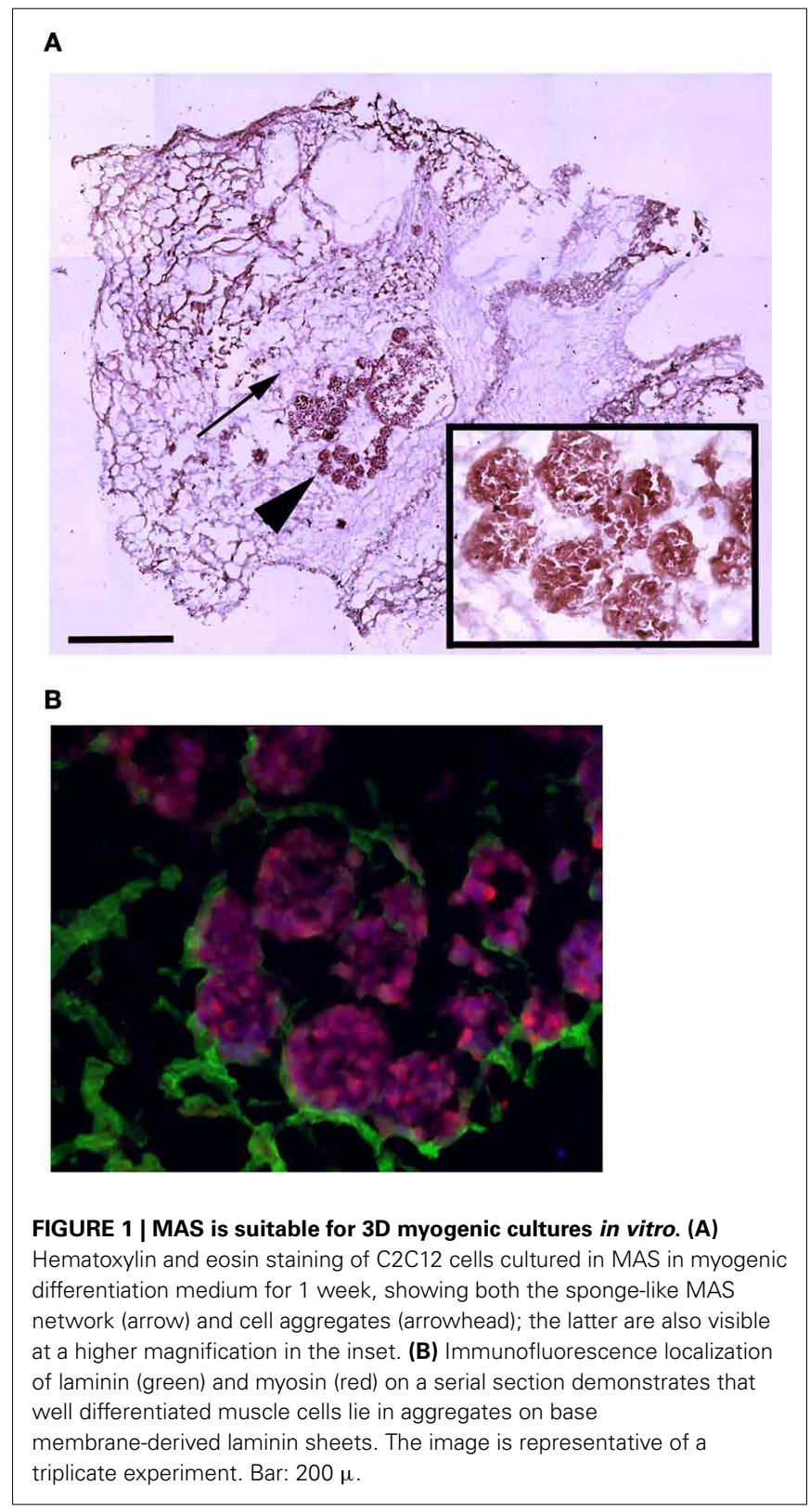

for culture models, which will allow the true in situ regenerative niche to be investigated, have been reviewed by Kirkpatrick (Kirkpatrick, 2014).

The definition of the microenvironment affecting both stem cell renewal and committed daughter cell differentiation is of particular relevance to tissue engineering (TE). TE represents an innovative approach based on the emulation of neoorganogenesis aimed at recreating a wide range of tissues to be used to replace lost tissues (Klumpp et al., 2010). A commonly applied definition of TE, provided by Langer and Vacanti, is "an interdisciplinary field that applies the principles of engineering and life sciences toward the development of biological substitutes that restore, maintain, or improve tissue function or a whole organ" (Langer and Vacanti, 1993). For TE purposes cells are often transplanted or seeded into a structure capable of supporting three-dimensional tissue formation. These structures, referred to as scaffolds, are critical, both ex vivo and in vivo, to recapitulate the niche and to support cell adhesion, survival and differentiation. Indeed, not only do scaffolds allow cell migration and/or attachment, but they also deliver and retain cells and biochemical factors, permit the diffusion of vital cell nutrients and exert mechanical and biological influences that control cell behavior (Macchiarini et al., 2008; Whitney et al., 2012). Scaffolds may be made of either natural or synthetic materials. Indeed, various derivatives of the extra cellular matrix (ECM) have been studied because they possess all the features of the ideal tissue-engineered scaffold or biomaterial, which include histocompatibility, bioactivity, porosity, degradability, non-toxicity and mechanical properties that match those of the original tissue (Borschel et al., 2004).

An alternative to the production of constructs composed of cells seeded into scaffolds is ECM. ECM can be used to support in situ regeneration, thereby relying on the bioactivity of autologous or heterologous biomaterial on autologous cells. Indeed, ECM is manufactured by the resident cells of each tissue and organ and is in a state of dynamic equilibrium with its surrounding microenvironment. We may assume, even without deciphering the complex three-dimensional organization of the structural and functional molecules of which it is composed, that ECM is biocompatible because cells produce their own matrix (Badylak, 2007). Recently, an increasing amount of attention has been paid to the use of ECM-based scaffolds for TE interventions. ECMbased scaffolds not only preserve the structure and molecular features of the native ECM, but also release matricryptic peptides during degradation. Matricryptic peptides affect cell motility, proliferation and differentiation, thereby greatly influencing the constructive remodeling of new tissue (Faulk et al., 2013). For these reasons, various forms of intact ECM have been used as biological scaffolds to promote the constructive remodeling of tissues and organs (Dahms et al., 1998; Meyer et al., 1998), with many of these ECM materials being marketed for a variety of therapeutic applications (Perniconi and Coletti, 2014; Teodori et al., 2014). Intact ECM is typically obtained by means of decellularization from explanted tissue in such a way as to create scaffolds that maintain the original spatial organization and biochemical composition. Tissue decellularization may be achieved in various ways, all of which eliminate the cellular compartment and leave a spatially and chemically preserved ECM (Crapo et al., 2011; Teodori et al., 2014).

We previously produced muscle acellular scaffolds (MAS) by means of decellularization at the whole organ scale of murine skeletal muscles. We characterized the in vivo response to grafted MAS and observed that such a construct provides a pro-myogenic environment (Perniconi et al., 2011). In particular, we reported that MAS orthotopically transplanted in mice was colonized by both inflammatory and stem cells and supported de novo muscle fiber formation (Perniconi et al., 2011). By definition MAS possesses only one component of the niche, i.e., the muscle ECM, being deprived of tissue specific cells and growth factors. In our previous experimental settings (Perniconi et al., 2011), as MAS was orthotopically grafted to replace a Tibialis anterior muscle (TA), the relative contribution to muscle formation by 


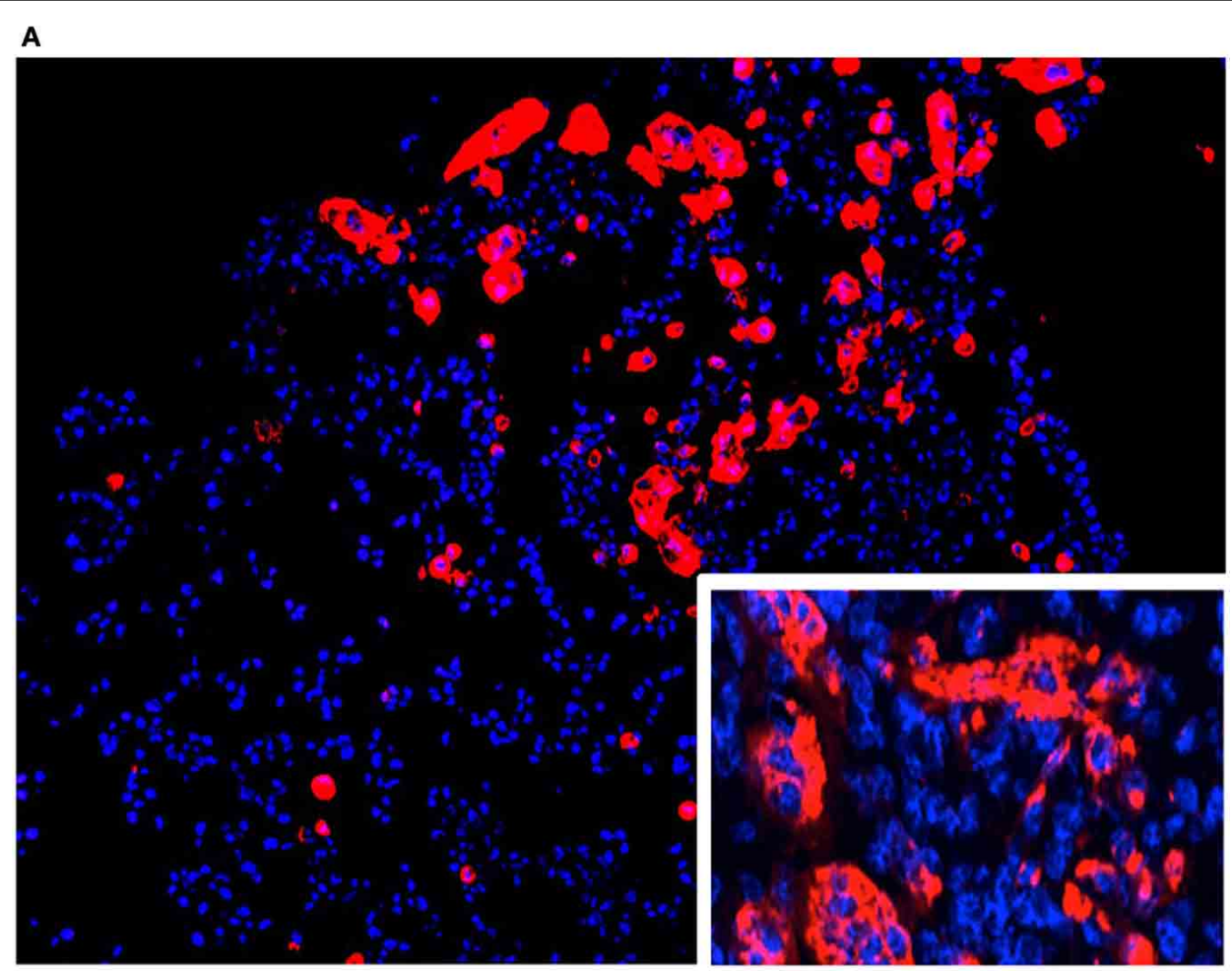

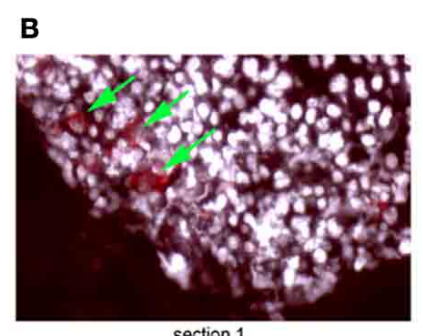

section 1

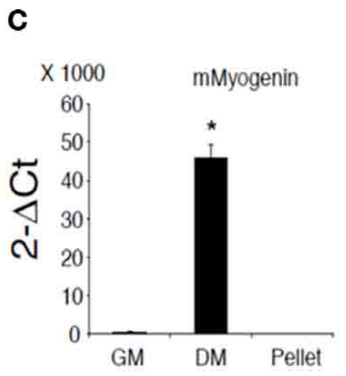

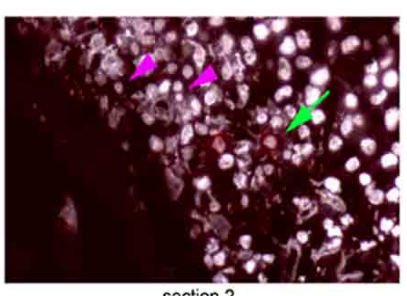

section 2

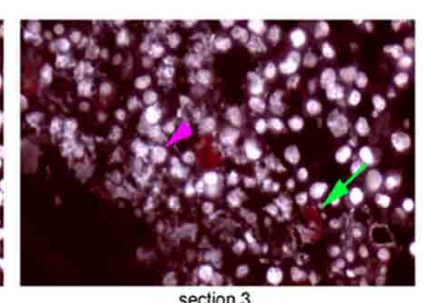

section 3
FIGURE 2 | C2C12 3D culture myogenic differentiation. (A)

Immunofluorescence analysis of all myosin expression (MF20 antibody, red) in pellets of $\mathrm{C} 2 \mathrm{C} 12$, whose nuclei are counterstained by Hoechst (blue), cultured for 5 days in a minimal medium consisting of DMEM supplemented with $1 \%$ BSA. The inset at a higher magnification shows myosin positive syncytia. (B) Serial sections of $\mathrm{C} 2 \mathrm{C} 12$ pellets (distance between section $=15 \mu \mathrm{m}$ ) following immunofluorescence analysis for myosin showing the appearance (green arrows) and disappearance (purple arrowheads) of the signal, suggesting that the dimension of the objects is of the order of magnitude of $30 \mu \mathrm{m}$. Nuclei are counterstained by Hoechst and post-processed to withe to ameliorate
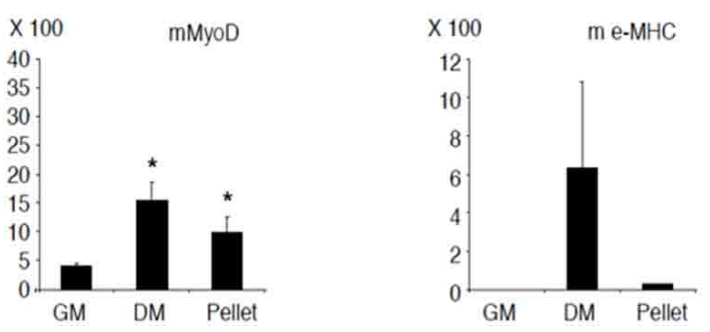

contrast. (C) Q-PCR of muscle markers expressed by $\mathrm{C} 2 \mathrm{C} 12$ pellets cultured in 1\% BSA for 5 days (pellet) as compared to $\mathrm{C} 2 \mathrm{C} 12$ 2D cultures in growth medium (GM) and differentiation medium (DM), used as a negative and positive control, respectively. From left to right: murine (m) myogenin, MyoD and embrionic (e) myosin heavy chain $(\mathrm{MHC})$. The mean \pm s.e.m. of triplicate samples is shown. ${ }^{*} p<0.05$ vs. GM, by Student's $t$-test. Culturing myogenic cells in $3 \mathrm{D}$ aggregates is sufficient to trigger a certain extent of myogenic differentiation. Therefore, whether MAS promotes muscle differentiation in serum-free medium (i.e., in the absence of pro-myogenic stimuli) cannot be clearly ascertained due to lack of proper 3D culture controls. 
the graft and the surrounding environment could not be fully assessed because both MAS and TA were of muscular origin. The aim of the present work was to investigate whether MAS per se is exclusively a pro-myogenic environment (which would mean its use is limited to muscle tissue engineering applications) or is compatible with other differentiation pathways. In order to achieve this aim, we analyzed, in vitro and in vivo, the interaction between MAS and both muscle and non-muscle cells and tissues, to determine whether MAS is necessary or sufficient to induce myogenesis regardless of its location.

\section{MATERIALS AND METHODS CELL CULTURES}

C2C12 mouse myoblasts were cultured in growth medium (GM), composed of Dulbecco's Modified Eagle Medium (DMEM) with $4.5 \mathrm{~g} / \mathrm{l}$ Glucose, L-Glutamine (Sigma), supplemented with 15\% fetal bovine serum (FBS), and $100 \mathrm{U} / \mathrm{ml}$ penicillin/100 microg/ml streptomycin (Invitrogen). For differentiation experiment positive controls, $\mathrm{C} 2 \mathrm{C} 12$ were cultivated in GM until they reached $80-90 \%$ of confluence on plastic Petri dishes, then were shifted to $2 \%$ horse serum (HS) medium (DM). Alternatively, $2 \times 10^{6}$
A

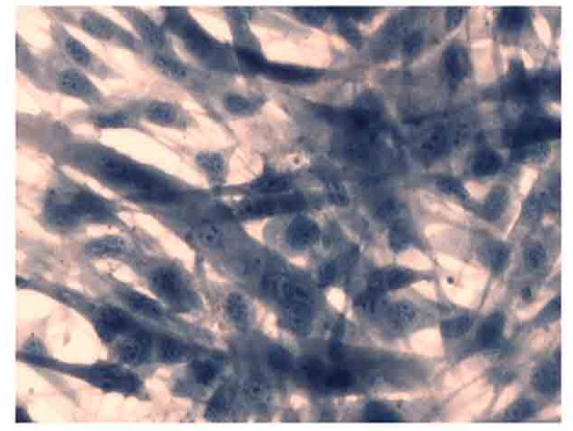

C

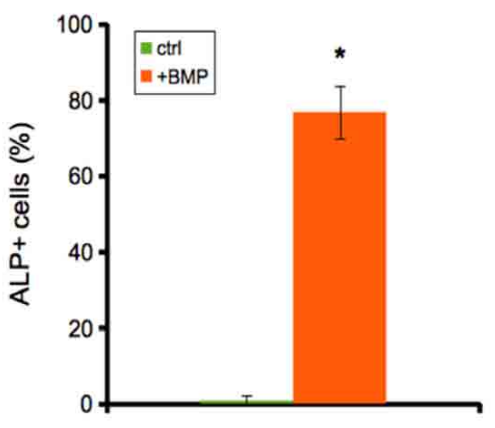

E

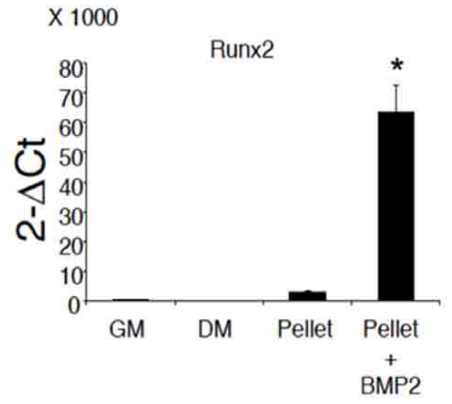

FIGURE 3 | BMP induces osteogenic differentiation both in 2D and 3D C2C12 and primary cultures. ALP staining of $\mathrm{C} 2 \mathrm{C} 12$ cultures on plastic in the absence (A) or presence (B) of $300 \mathrm{ng} / \mathrm{ml} \mathrm{BMP-2}$ for 5 days, showing that $\mathrm{C} 2 \mathrm{C} 12$ possess osteogenic potential when cultured in the presence of BMP. The cells were counterstained with Hematoxylin and the osteoblasts (red cells) were quantified (C). The mean \pm s.e.m. of quadruplicate samples is shown. ${ }^{*} p<0.05$ vs. GM, by Student's t-test. (D) A similar myogenic to osteogenic conversion upon BMP treatment occurs in myogenic cell primary cultures: an ALP+ cell is visible in the photomicrograph; the inset shows the myogenic lineage of primary
B

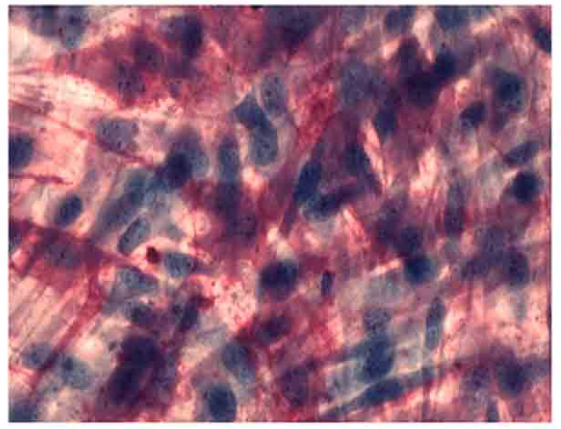

D

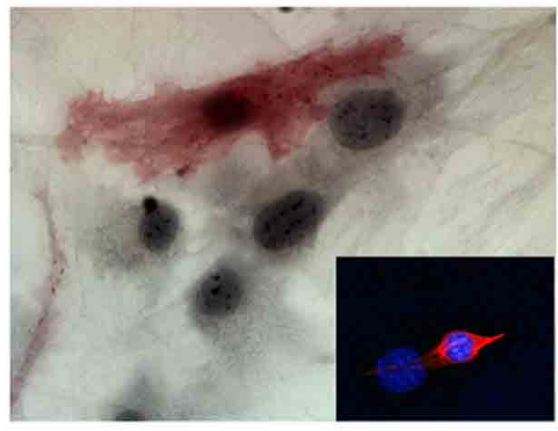

ALP

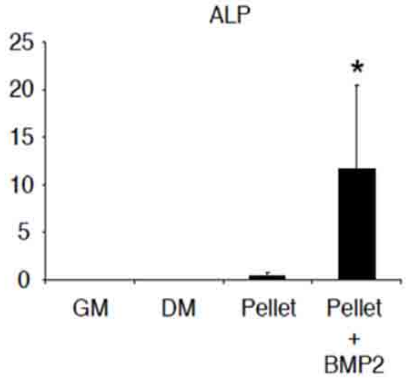

cultures from skeletal muscle by desmin expression (red), while nuclei were counterstained by Hoechst (blue). Nuclear size and shape discriminate myoblasts/osteoblasts from fibroblasts. Bar: $50 \mu$. (E) Q-PCR of bone markers expressed by $\mathrm{C} 2 \mathrm{C} 12$ pellets cultured in 1\% BSA for 5

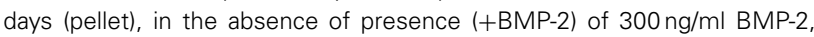
as compared to $\mathrm{C} 2 \mathrm{C} 12$ 2D cultures in growth medium (GM) and differentiation medium (DM), both used as a negative controls for osteogenic markers. From left to right: murine runt-related transcription factor 2 (Runx2) and alkaline phosphatase (ALP). The mean \pm s.e.m. of triplicate samples is shown. ${ }^{*} p<0.05$ vs. GM, by Student's $t$-test. 
C2C12 cells were resuspended in 50 microL of GM and injected within a MAS derived from a murine TA (see the paragraph Decellularization of skeletal muscle, below). The cells were treated for 5-7 days with $2 \%$ HS (horse serum) in the absence or presence of BMP-2.

\section{DECELLULARIZATION OF SKELETAL MUSCLE}

For decellularization of skeletal muscle we dissected TA or Extensor digitorum longus (EDL) and immediately incubated them in sterile $1 \%$ SDS in distilled water for 48 and $24 \mathrm{~h}$, respectively, at RT under slow rotation. At least $10 \mathrm{ml}$ of SDS solution
A

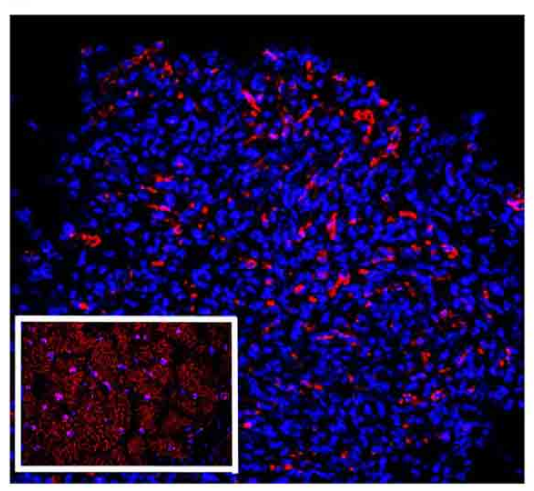

C

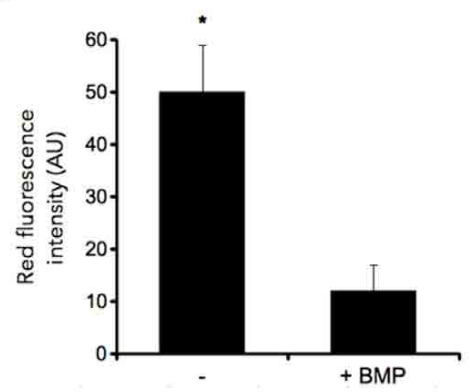

D

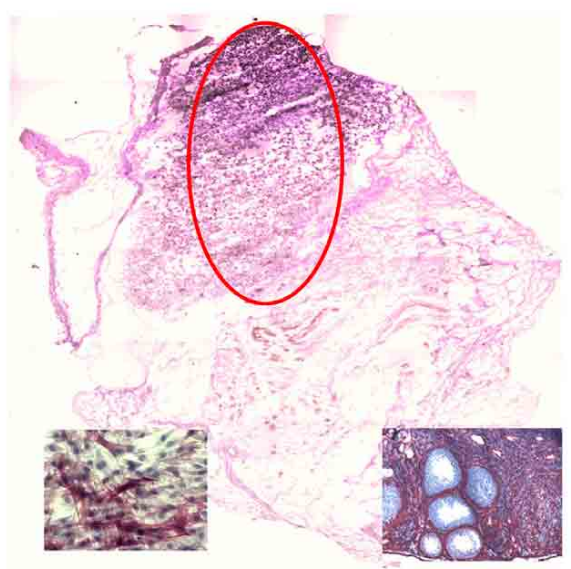

FIGURE 4 | MAS does not irreversibly commit C2C12 cells to a myogenic fate. Immunofluorescence analysis of all myosin expression (MF20 antibody, red) in $\mathrm{C} 2 \mathrm{C} 12$ cells, whose nuclei are counterstained by Hoechst (blue), cultured for 5 days in MAS in a medium consisting of DMEM supplemented with $2 \% \mathrm{HS}$ in the absence (A) or presence (B) of $300 \mathrm{ng} / \mathrm{ml} \mathrm{BMP-2}$. The inset in (A) shows a muscle section used as a positive control. Myosin positive cells (red) are visible in both cases; however, myogenic differentiation seems to occur predominantly in tightly aggregated cells, since the scattered, ALP positive cells do not express myosin in serial sections (see the arrows in $\mathbf{B}, \mathbf{E}$ ). (C) Quantification of myosin (red fluorescence) from quadruplicate samples as above. Mean \pm

\section{B}

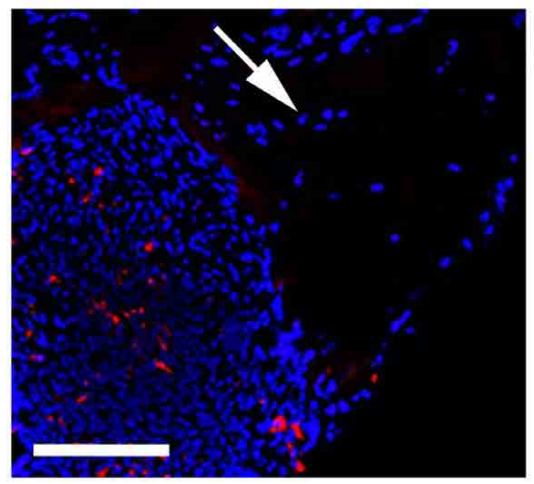

E

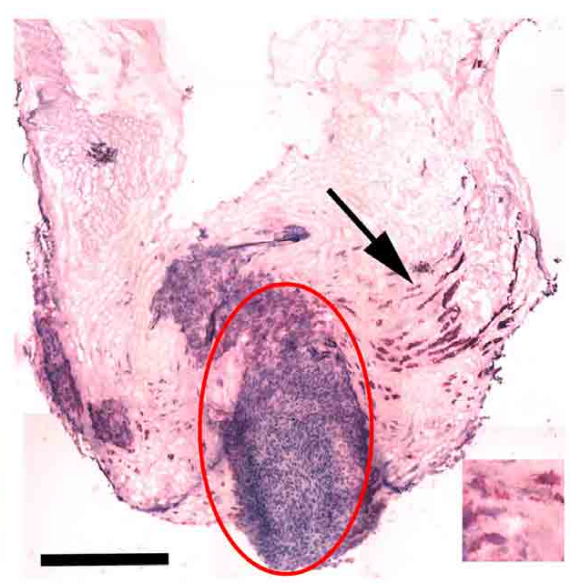

s.e.m. ${ }^{*} p<0.05$ vs. GM, by Student's t-test. As shown by ALP staining, and hematoxylin counterstaining, of $\mathrm{C} 2 \mathrm{C} 12$ cells cultured in MAS in the absence (D) or presence (E) of BMP, C2C12 do express ALP but only in the presence of BMP. The bulk cell aggregates deriving from the original injection of cell suspension into the MAS are indicated by light ellipses. The insets in (D) represent positive controls: an ovary section (left) and BMP-treated $\mathrm{C} 2 \mathrm{C} 12$ cells (right); the inset in (E) shows ALP expressing cells at a higher magnification. The latter are abundant in the region in which MAS was colonized by cells (arrow in E), which are likely to have migrated out of the cell aggregate visible in the center of the MAS. Black bar $=500 \mu$, white bar $=100 \mu$. 
was used for each pair of muscles. After the decellularization procedure, the muscles were thoroughly washed by means of 3 incubations lasting at least $30 \mathrm{~min}$ each in sterile PBS. Decellularized scaffolds were used on the same day as they were produced or were stored for specific experiments.

\section{ANIMALS AND SURGICAL PROCEDURES}

Adult sex-matched BALB/C mice were used throughout this study as both donors and hosts. Mice were treated according to the guidelines of the Institutional Animal Care and Use Committee. Donor animals were sacrificed before skeletal muscle removal,

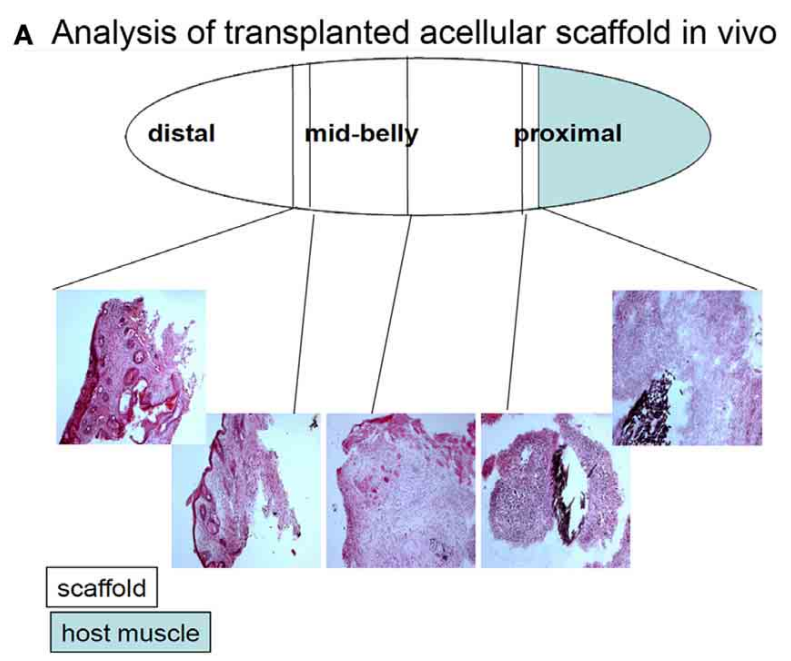

\section{B Renal capsule grafting technique}

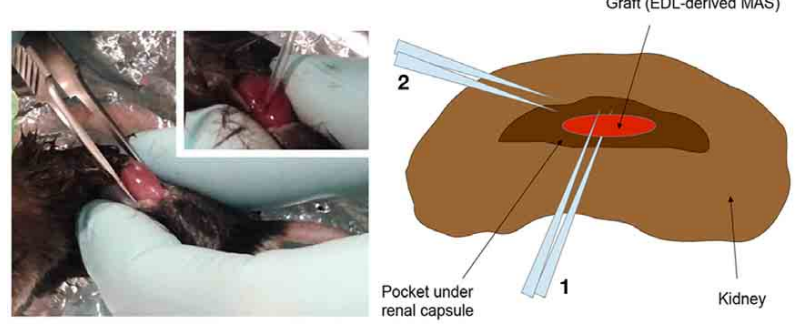

FIGURE 5 | (A) Analysis of transplanted acellular scaffold in vivo. The Tibialis anterior muscle was removed, with the exception of a proximal fragment (light blue) and the MAS (open ellipse) was sutured to the muscle at the proximal end and to the tendon at the distal end. The black silk suture knots, visible in the hematoxylin and eosin stained cryosections, were used as a reference of the graft extremities. The first third, second third and last third of the graft, starting from the proximal region, were defined as the proximal, mid-belly and distal parts of the grafted MAS, respectively. (B) Renal capsule grafting technique. The kidney was exposed by dorsal skin incision (picture) and the renal capsule cut lengthwise for about $5 \mathrm{~mm}$; a pocket was created under the connective tissue renal capsule by using a fire polished Pasteur pipet (picture inset). The graft was inserted into the pocket by mean of forceps and the tip of the pipet ( 2 and 1 in the drawing, respectively). For this specific experiment, the grafted MAS was obtained from an extensor digitorum longus muscle (Graft, EDL-derived MAS) because of the size of the latter was compatible with the grafting technique. while host animals were anaesthetized before muscle dissection and MAS engraftment. The transplantation procedure is described in detail below. TA acellular scaffolds were used to replace TA of inbred, age- and sex-matched wild type mice. The grafts were subsequently dissected from the host 2 weeks following transplantation. The surgical procedures have been described previously (Perniconi et al., 2011).

Scaffold grafting within the renal capsule. Animals were weighed and anaesthetized. After a small incision had been made in the body wall, the kidney popped out of the hole in the body wall when pressure was applied on either side of the kidney using the forefinger and thumb. An incision of approximately $5 \mathrm{~mm}$ was made in the renal capsule. Then a glass Pasteur pipette, which had been drawn thin and fire-polished with a rounded closed end, was used to obtain a capsule pocket by manipulating the pipette point tangential to the kidney in such a way as to detach the renal capsule. The scaffold was inserted into the pocket under the capsule using the polished glass pipette. After replacing the kidney within the peritoneal cavity, the body wall was sutured with 1 or 2 stitches of silk thread.

Scaffold grafting under the xiphoid process. Animals were weighed and anaesthetized. A small incision was made under the sternum. Without touching the muscle diaphragm, the scaffold was attached with a suture to the xiphoid process in order to suspend it within the peritoneal cavity in close contact with cartilage tissue. The body wall was sutured with 1 or 2 stitches of silk thread.

\section{HISTOLOGICAL ANALYSIS}

At the end of the experimental period the pellets within the scaffolds were frozen within OCT mounting medium (Leica) in liquid nitrogen-cooled isopentane. Cryosections $(8 \mu \mathrm{m})$ were obtained using a Leica cryostat. For histological analysis, the sections were stained with hematoxylin and eosin using standard methods (Sigma). Alternatively, cryosections were stained with $0.05 \%$ Toluidine blue $(\mathrm{BDH})$ for $30 \mathrm{~min}$. Photomicrographs were obtained using an Axioscop 2 plus system equipped with an Axiocam HRc (Zeiss) at $1300 \times 1030$ pixel resolution.

\section{ALKALINE PHOSPHATASE (ALP) ASSAY FOR THE CHARACTERIZATION OF OSTEOBLASTIC PHENOTYPES}

A leukocyte ALP kit (Sigma-Aldrich) was used for ALP staining according to the recommended protocol. Cells were counterstained with $0.05 \%$ neutral red (Sigma). They were then fixed by immersion in fixative solution (citrate-acetone-formaldehyde) for $30 \mathrm{~s}$, gently rinsed with water and put in an alkaline-dye mixture (sodium nitrite solution, FRV-Alkaline solution, deionized water, Naphthol AS-BI Alkaline solution) for $15 \mathrm{~min}$. The samples were then rinsed for $2 \mathrm{~min}$ in deionized water and counterstained for 2 min with Hematoxylin solution Gill N.3, rinsed in tap water and air dried.

\section{IMMUNOFLUORESCENCE ANALYSIS}

Transverse cryosections were rinsed in PBS for $5 \mathrm{~min}$ at RT and then incubated with Blocking minBuffer (1\%BSA, 10\% Goat Serum in PBS) for $1 \mathrm{~h}$ at RT. The samples were washed in PBS and incubated with primary antibody (Ab) MF20 (Mouse 
IgG2b myosin Hybridoma bank) at a 1:50 dilution in PBS, and polyclonal anti-laminin Ab (policlonal Rabbit Sigma) at a 1:50 dilution in PBS. The sample were incubated with the secondary $\mathrm{Ab}$ anti-mouse-Dylight 549 and anti rabbit AlexaFluor 488 a 1:400 dilution in PBS for $1 \mathrm{~h}$. Alternatively, laminin Ab was detected by anti-rabbit-Alexa $568 \mathrm{Ab}$. Secondary Abs were used to detect endogenous IgG on cryosections of the grafted material using anti-mouse-Alexa 488. Pre-immune serum was used for the negative control. Finally, $0.5 \mathrm{ug} / \mathrm{ml}$ Hoechst 33342 (Sigma) was used to counterstain cell nuclei. Photomicrographs were obtained by means of an Axioskop 2 plus system (Zeiss) or a Leica Leitz DMRB microscope fitted with a DFC300FX camera for confocal analysis (Leica).

Quantitative analysis was performed on fluorescence images of 10 randomly chosen microscopic fields acquired in the red channel. Post-processing of the images was performed using Adobe Photoshop and Scion Image Softwares (the latter, a software originally developed with the name of NIH Image at NIH, Bethesda,

\section{A}

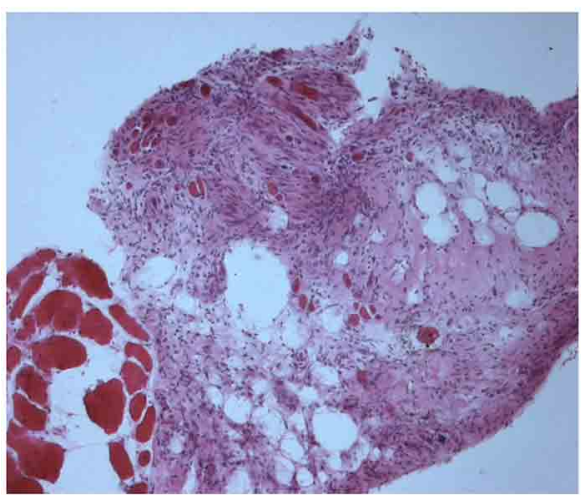

C

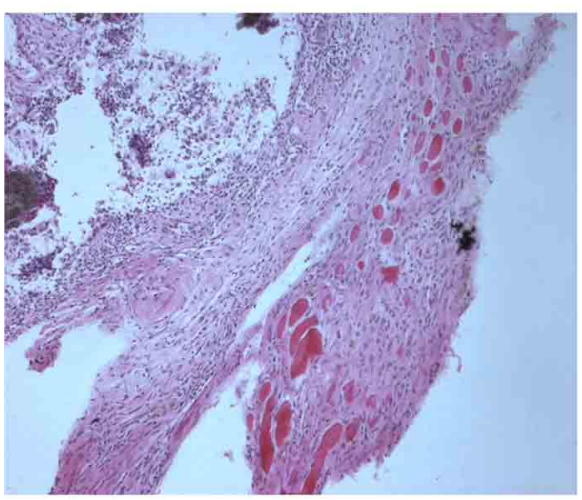

E

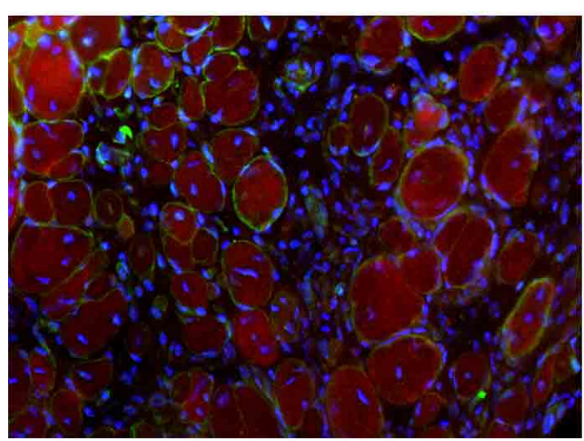

FIGURE 6 | MAS is sufficient to support muscle regeneration in volumetric muscle loss. Hematoxylin and eosin staining of cross-cryosections of MAS grafted in the place of the Tibialis anterior in a syngeneic mouse and analyzed at the level of distal $(\mathbf{A}, \mathbf{C})$ and mid-belly $(\mathbf{B}, \mathbf{D}, \mathbf{F})$ muscle sections (for the definition of these positions, refer to

Figure 5A), 2 (A,B) and 3 (C,D,F) weeks following transplantation. Numerous
B

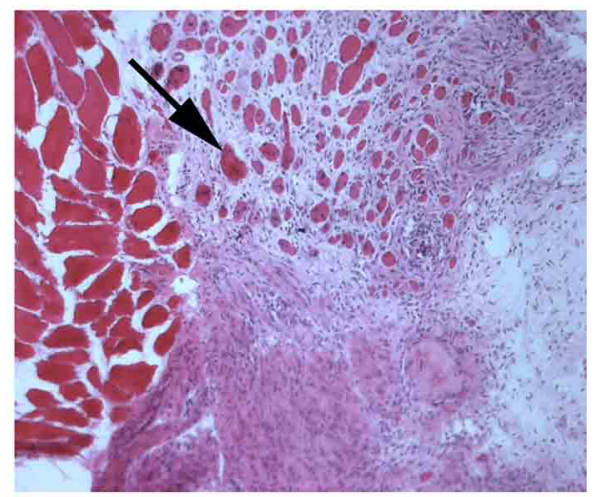

D

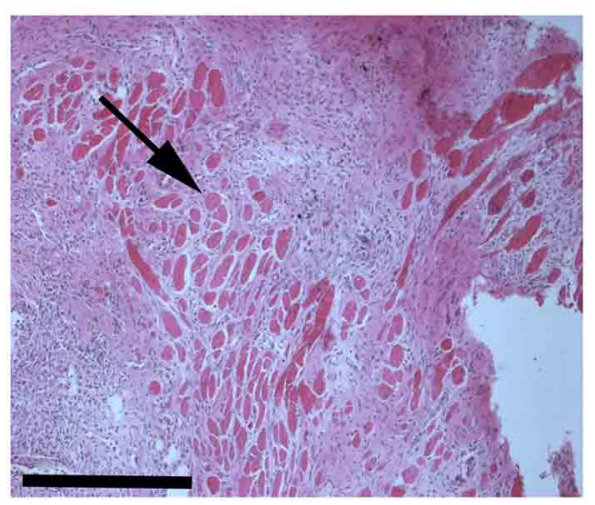

$\mathbf{F}$

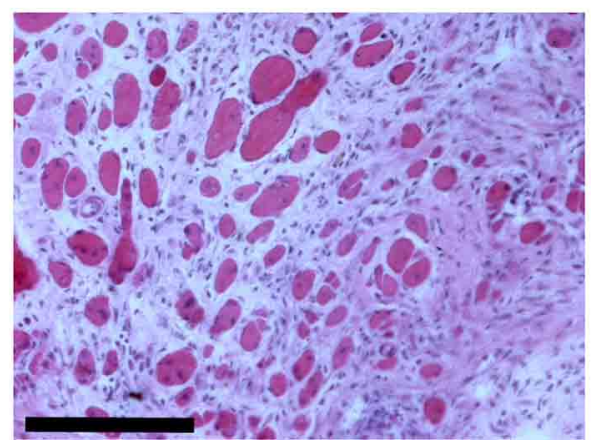

regenerating muscle fibers (arrow), characterized by centrally located nuclei, are visible within the inflammatory infiltrate. Multiple and/or centrally located nuclei in the same rose cytoplasm indicate bona fide nascent muscle fibers (F), as confirmed by sarcoglycan (green) and myosin (red) expression around centrally located nuclei (blue) shown by immunofluorescence in (E). The picture is representative of triplicate experiments. Bar $=200 \mu$. 


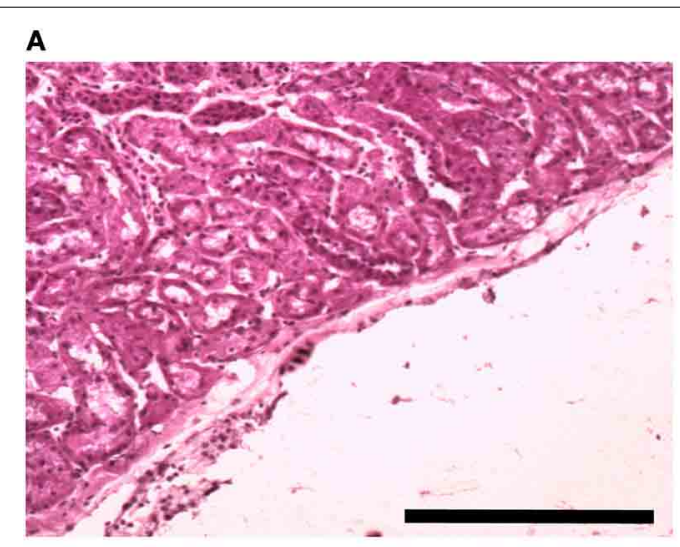

B

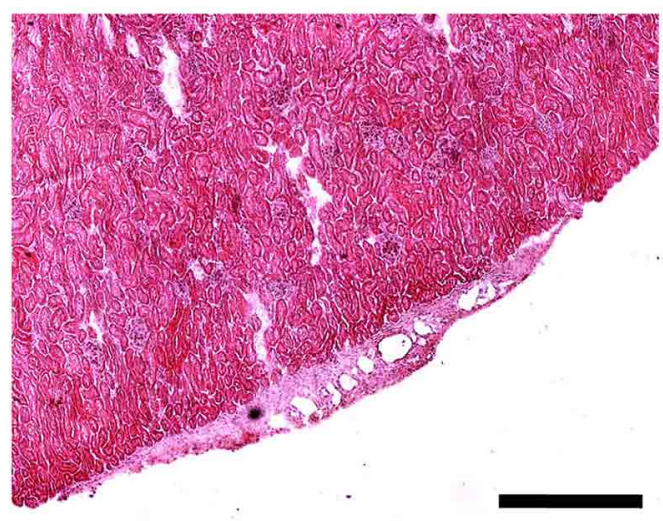

C

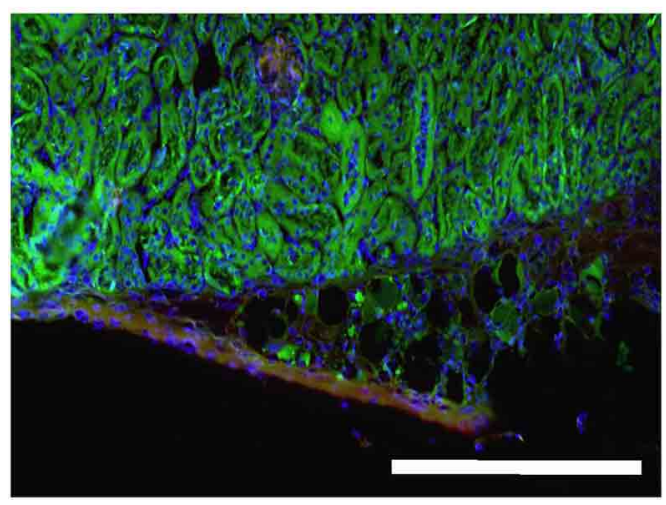

FIGURE 7 | MAS is not sufficient to promote myogenesis within the renal capsule. Hematoxylin and eosin staining of cross-cryosections of a peripheral region of the kidney and its renal capsule in the absence (A) or in the presence (B) of grafted MAS, 2 weeks following transplantation. The immunofluorescence analysis (C) for laminin (green) and myosin (red) shows the absence of muscle fibers in the grafted MAS. Note that the glomeruli are strongly autofluorescent. Nuclei are stained by Hoechst (blue). Bar $=200 \mu$. The picture is representative of triplicate experiments.

is freely downloadable at http://rsb.info.nih.gov/ij/index.html). Modifications were the same for all images and consisted in a conversion to gray scale, followed by the measure of the mean fluorescence calculated on the whole field. The values were normalized by the area examined and expressed as arbitrary units $(\mathrm{AU})$. Values deriving from the 10 sampled fields were averaged and the result was considered representative of one sample. At least four independent replicates were analyzed and averaged.

\section{QUANTITATIVE REAL-TIME REVERSE TRANSCRIPTION POLYMERASE CHAIN REACTION (RT-qPCR)}

Total mRNA was isolated using an RNeasy mini kit (Qiagen, Courtaboeuf, France) or a TRIzol ${ }^{\circledR}$ reagent method (Invitrogen) as described by the manufacturers. DNAse-treated RNA was reverse transcribed with SuperScript ${ }^{\circledR}$ III RT (Invitrogen), the cDNA obtained was amplified using TaqMan ${ }^{\circledR}$ or SYBR ${ }^{\circledR}$ Green chemistries (Applied Biosystems by Life Technologies, Courtaboeuf, France), and monitored with the 7500HT Fast Real-Time PCR System (Applied Biosystems). Primers used for RT-qPCR are listed below. Amounts of cDNA of interest were normalized to that of GAPDH $(\Delta \mathrm{Ct}=\mathrm{Ct}$ gene of interest-Ct GAPDH). Results were reported as relative gene expression (2- $\Delta \mathrm{Ct})$. The following couples of primers were used for murine $(\mathrm{m})$ or human (h) genes: (1) glyceraldehyde 3-phosphate dehydrogenase (mGAPDH: forward CTGAGCAAGAGAGGCCCTA; reverse TATGGGGGTCTGGGA TGGAA; (2) runt-related transcription factor 2 (mRUNX2: forward TTGACCTTTGTCCCAATGC; reverse AGGTTGGAGG CACACATAGG); (3) alkaline phosphatase (mALP: forward TGTCTGGAACCGCACTGAACT; reverse CAGTCAGGTT GTTCCGATTCAA); (4) glyceraldehyde 3-phosphate dehydrogenase (GAPDH: forward CCAGCAAGAGCACAAGAGGA; reverse AGATTCAGTGTGGTGGGGG); (5) runt-related transcription factor 2 (hRUNX2: forward GAATCCTCCACCCACCCAAG; reverse AATGCTGGGTGGCCTACAAA); (6) bone sialoprotein 2 (hIBSP: forward CCATTCTGGCTTTGCATCCG; reverse GACAAGAAGCCTATTACTTTGC); (7) bone sialoprotein 2 (hOC: forward GTGCAGAGTCCAGCAAAGGT; reverse TCCCA GCCATTGATACAGGT); (8) alkaline phosphatase (hALP: forward GTGCAGAGTCCAGCAAAGGT; reverse TCCCAGCCAT TGATACAGGT); (9) myogenin (forward GCACTGGAGTTCGG TCCCAA; reverse TATCCTCCACCGTGATGCTG); (10) Myo D (forward ACCCAGGAACTGGGATATGGA; reverse AAGTC GTCTGCTGTCTCAAA); (11) embryonic myosin heavy chain (e-MHC: forward CGTCTGCTTTTGGCAA; reverse TGGTC GTAATCAGCAGCA). RUNX2 and ALP represent classic markers of osteogenic differentiation (Coquelin et al., 2012; Leotot et al., 2013), while MyoD, myogenin and myosin represent the standard markers for myogenic differentiation (De Arcangelis et al., 2003, 2005; Naro et al., 2003; Musaro et al., 2007).

\section{RESULTS}

\section{MAS IS SUITABLE FOR 3D MYOGENIC CELL CULTURES}

To assess whether MAS supports cell attachment, survival and differentiation, we cultured myogenic $\mathrm{C} 2 \mathrm{C} 12$ cells in MAS in DM for 1 week. C2C12 is a multi-potent cell line derived from muscle satellite cells, and is thus primarily myogenic. On the other hand, MAS is a muscle-derived biomaterial which we had previously demonstrated is pro-myogenic in vivo, without knowing whether it retained the same properties in vitro. In these 
conditions, $\mathrm{C} 2 \mathrm{C} 12$ cells showed the tendency to aggregate in a cell-cell fashion (Figure 1A), even though they clearly came into contact with the MAS laminin (Figure 1B), when cultured within MAS. The cells survived for several days in culture and were able to differentiate, i.e., to express markers of fully differentiated muscle fibers (Figure 1B). Therefore, we considered that MAS was sufficiently stable to support cell cultures and was compatible with myogenic differentiation.

$\mathrm{C} 2 \mathrm{C} 12$ are cells that fuse with each other during differentiation to form myotubes in vitro. As expected, cell-cell contact represents a condition leading to fusion for these cells (Rochlin et al., 2010). However, this is not a sufficient trigger when $\mathrm{C} 21 \mathrm{C} 2$ are cultured in a minimal medium supplemented with $1 \%$ BSA in 2D cultures, a condition that is not associated with their myogenic differentiation and cell fusion. On the other hand, 3D cultures of C2C12 are still poorly characterized (Carosio et al., 2013). Therefore, we decided to characterize the effects of 3D culturing per se on $\mathrm{C} 2 \mathrm{C} 12$ differentiation with the aim to better interpret the C2C12 3D cultures within MAS. We noticed that 3D C2C12 aggregates obtained by pelleting $\mathrm{C} 2 \mathrm{C} 12$ before placing them in culture, displayed several markers of myogenic differentiation both in 2\% HS in 1\% BSA (Figure 2 and data not shown). In particular, C2C12 2D cultures in $2 \%$ HS (the gold standard myogenic differentiation for this type of cells) were compared to $\mathrm{C} 2 \mathrm{C} 12$ pellets cultured in

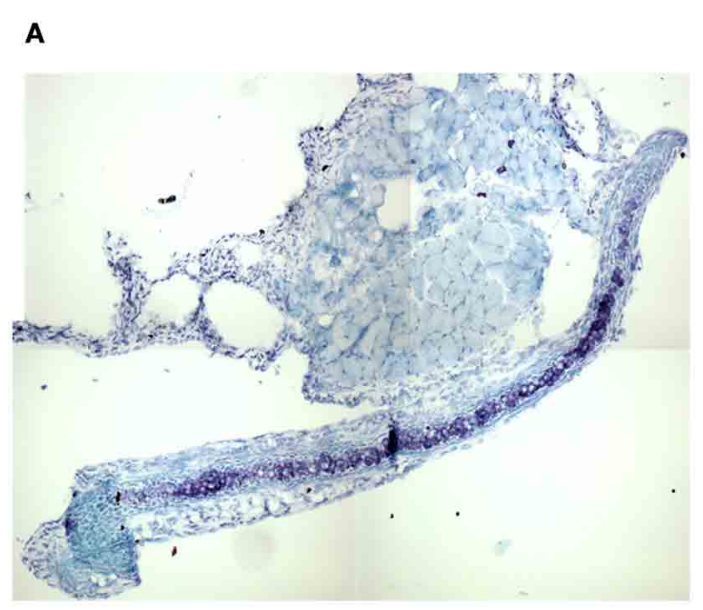

B

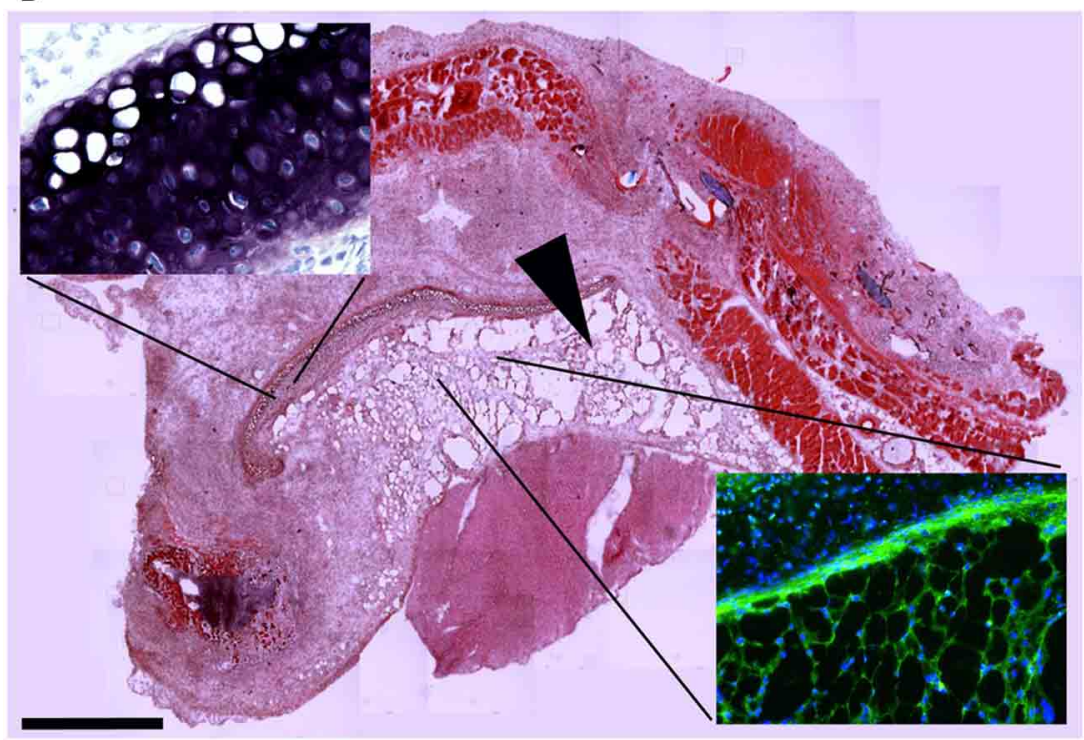

FIGURE 8 | MAS grafted under the xiphoid process. (A) Toluidine blue staining of the region of the xiphoid process without grafting. Cartilage tissue (arrow) is strongly metachromatic. (B) Hematoxylin and eosin staining of the same region including grafted MAS, 2 weeks following transplantation. The absence of muscle fibers in the grafted MAS (arrowhead) is evident when the latter is compared with skeletal muscles of the pectoral muscles in the upper region of the image. The insets, at a higher magnification, show: (bottom right) immunofluorescence analysis for laminin (green) and myosin (red)_nuclei are stained by Hoechst (blue)—on a serial section demonstrating the absence of muscle fibers in the grafted MAS; (upper left) toluidine blue staining showing the position of the xiphoid process, whose matrix is highly metachromatic. The picture is representative of triplicate experiments. 
1\% BSA. The latter showed: not detectable myogenin but significant MyoD expression (Figure 2C), which was sufficient to trigger myosin expression (detectable with an anti-pan-myosin antibody such as MF20, Figure 2A). Among the myosin isoforms possibly expressed by $\mathrm{C} 2 \mathrm{C} 12$, we found low embryonic myosin expression (Figure 2C), suggesting that other isoforms typical of more mature fibers are expressed, in spite of the absence of elongated myotube formation (Figure 2B). Such aberrant differentiation resembled that of rhabdomyosarcomas and the $\mathrm{Rb}$ cell line (Wang et al., 2010). However, since a 3D organization was

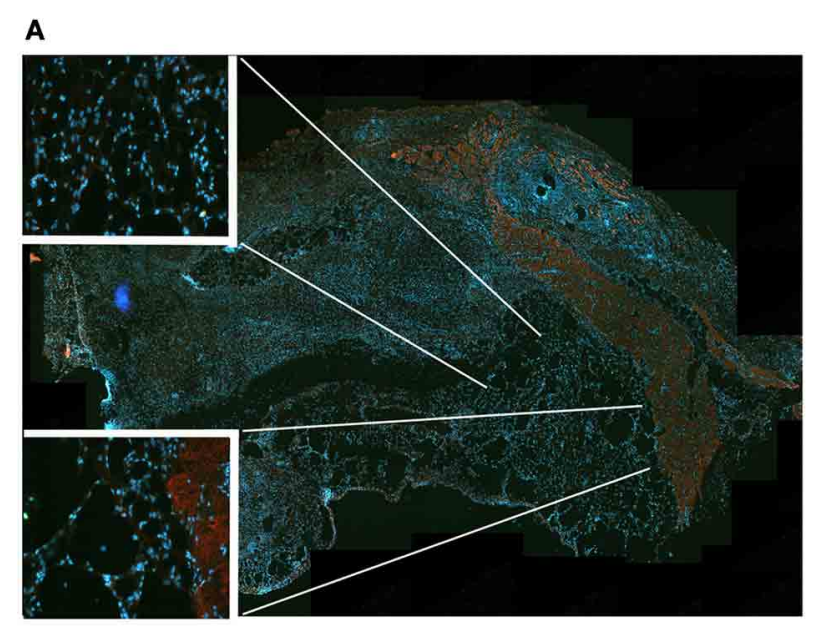

B

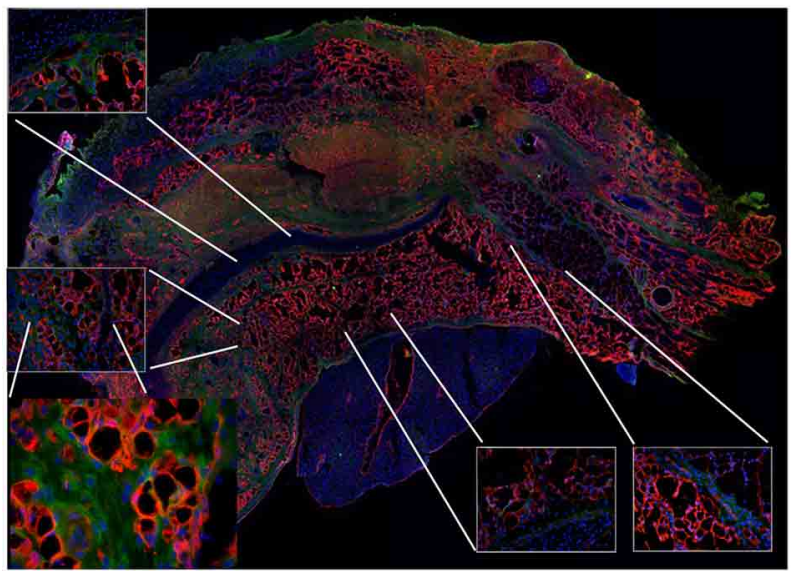

FIGURE 9 | MAS is not sufficient to promote myogenesis under the xiphoid process. (A) The panel represents a reconstruction (with insets at a higher magnification) of the whole region, following an immunofluorescence analysis for myosin (red) and nuclei (blue), once again demonstrating the absence of muscle markers in the spongy structure of MAS; this is in contrast to the pectoral muscles in the upper region of the image, which represent a positive control for the immunofluorescence reaction. (B) Reconstruction (with insets at a higher magnification) of the whole region, following an immunofluorescence analysis for laminin (red), immunoglobulins (green) and nuclei (blue), which demonstrates MAS colonization by cells during an inflammatory process. All the analyses in this figure were performed 2 weeks following transplantation, which is a sufficient amount of time for muscle regeneration in MAS grafted to replace a Tibialis muscle. The picture is representative of triplicate experiments. Bar $=400 \mu$. per se myogenic to a certain extent, a 3D C2C12 culture in MAS in $1 \%$ BSA was considered to be unsuitable to test whether MAS was sufficient to induce differentiation under minimal medium, conditions owing to the lack of an adequate negative control in vitro.

\section{MAS DOES NOT IRREVERSIBLY INDUCE 3D CELL CULTURES TO A MYOGENIC FATE}

Both $\mathrm{C} 2 \mathrm{C} 12$ cells and muscle primary cell cultures, while committed to a myogenic lineage, differentiate into osteoblasts in the presence of BMP (Katagiri et al., 1994; Friedrichs et al., 2011). We confirmed this notion for 2D C2C12 and primary satellite cells obtained from murine skeletal muscle and cultured for 5 days in $2 \% \mathrm{HS}$ supplemented with $300 \mathrm{ng} / \mathrm{ml} \mathrm{BMP-2}$ (Figures 3A-D). BMP-treated cells displayed loss of myogenic differentiation, such as multinucleated myotube formation (Figure 3A) in favor of a potent pro-osteogenic conversion as demonstrated by the presence of non-fused, ALP expressing cells (Figures 3B-D). Worth noting BMP-2 effects on standard osteogenic markers (Coquelin et al., 2012; Leotot et al., 2013) were still potent in 3D C2C12 cultures (Figure 3E), indicating that 3D cultures are not impermeable nor insensitive to BMP treatment and suggesting to use $\mathrm{BMP}$ as a non-myogenic cue to test whether MAS irreversibly commit $\mathrm{C} 2 \mathrm{C} 12$ to a non-myogenic fate.

To this purpose, we treated $\mathrm{C} 2 \mathrm{C} 12$ cultured in MAS for 5 days within $2 \% \mathrm{HS}$ in the absence or presence of $300 \mathrm{ng} / \mathrm{ml}$ BMP-2. While C212 in MAS accumulated myosin and did not express ALP (Figures 4A,D), the same cells showed significantly reduced myosin expression and differentiated in ALPexpressing osteoblasts in the presence of BMP (Figures 4B,C,E). Interestingly, ALP expression was stronger in those cells that displayed migratory activity by leaving the bulk cell aggregate and becoming isolated cells (Figure 4E, inset). Thus, MAS supports at least two differentiation pathways for cells of mesenchymal origin and, while participating in the muscle environment in vivo, does not suppress the pro-osteogenic stimulus induced by BMP-2 in vitro.

\section{MAS PROMOTES MUSCLE REGENERATION IN VOLUMETRIC MUSCLE LOSS}

To assess in vivo whether MAS itself is inherently myogenic, we grafted the MAS both orthotopically (i.e., replacing a Tibialis anterior) and ectopically (i.e., within the renal capsule or underneath the xiphoid process). The Figure 5 illustrates these procedures, that are described in detail elsewhere and represent standard in vivo approaches to test xeno- or auto-grafts (Mericskay et al., 2004; Perniconi et al., 2011).

The presence of muscle fiber formation within orthotopically grafted MAS (Figures 6A-D) confirmed our previous in vivo results (Perniconi et al., 2011). Within 2 weeks from transplantation MAS was colonized by cells and showed the presence of nascent muscle fibers characterized by centrally located nuclei and muscle fiber specific markers such as myosin and sarcoglycan (Figures 6E,F), thereby demonstrating that MAS represents an environment that is compatible with neo-myogenesis. We found it striking that MAS alone, i.e., an empty scaffold even though of muscle origin, was colonized by cells and hosted new muscle 
formation, suggesting that it represents a pro-myogenic niche per se. To verify whether MAS was sufficient to induce myogenesis, we grafted MAS in anatomically different regions, i.e., the renal capsule and the peritoneal cavity under the xiphoid process. The renal capsule represents the gold standard for in vivo transplantation and assessment of allografts survival, bioactivity and function, because it is a highly vascularized environment that lends itself to the rapid integration and nutrition of the grafts. Two weeks following transplantation, we found grafted MAS (derived from EDL muscle for this specific experiment) within the renal capsule, which retained its sponge-like, lamininbased structure. While we observed that numerous cells came into contact with and colonized MAS, we did not detect any overt differentiated muscle fiber, by either the morphological or immunofluorescence analysis of muscle fibers (Figure 7).

To confirm this result, we grafted MAS under the xiphoid process by suturing it to the latter. In physiological conditions under the xiphoid process, which is a cartilaginous organ enveloped by connective tissue, there is the empty intraperitoneal space and the liver (Figure 8A). When grafted in this position, MAS was recognized by its sponge-like structure but could not be confirmed as a site of neo-myogensis, even though many cells did colonized the MAS and interacted with its laminin matrix (Figure 8B). Most of the cells migrating within the MAS and along the laminin are, in fact, likely to have been inflammatory cells, as demonstrated by the presence of abundant immunoglobulins (Figure 9A), which is consistent with our previously published findings. As a result, while myosin positive muscle tissue is visible in the analyzed sections, this is clearly not deriving from the grafted scaffold, on the basis of its histology and anatomical localization, which is distant and not in continuity with the grafted MAS (Figure 9B).

All together, the aforementioned results indicate that MAS per $s e$ is not sufficient to induce myogenesis in vivo, but it requires the presence of surrounding muscles to show robust myogenesis, an effect further increased if MAS is seeded with myogenic cells before engraftment.

\section{DISCUSSION}

In tissue engineering interventions, grafting of decellularized tissues or organs, such as MAS, is an increasingly widespread approach in pre-clinical and clinical settings (Badylak et al., 1998, 2013; Perniconi and Coletti, 2014; Teodori et al., 2014). In particular, ECM of muscle origin has been proposed as en efficient scaffold for organ-scale reconstruction following volumetric muscle loss (Ott et al., 2008; Perniconi et al., 2011). When MAS is orthotopically grafted in mouse to replace a skeletal muscle, de novo myogenesis is observed within a few weeks, probably as a result of MAS colonization by stem cells of host origin with myogenic potential (Perniconi et al., 2011). However, the relative contribution to muscle formation by the graft and the surrounding environment cannot be fully understood using this approach, because both are of muscular origin. In order to verify whether MAS possesses pro-myogenic properties per se, i.e., regardless of the site of transplantation, we grafted MAS in a heterotopic position in syngeneic mice. Using this approach, here we demonstrate that MAS is neither sufficient nor necessary for myogenesis. Indeed, when MAS is transplanted within the renal capsule or the peritoneal cavity under the xiphoid process it is colonized by an abundant cell infiltrate but does not display any regenerating fiber within its laminin network. These results demonstrate that MAS is stable in anatomical sites other than the skeletal musculature, but does not provide enough signals to trigger myogenesis by the colonizing cells. By cultivating C2C12 cells in 3D aggregates, we showed that the $3 \mathrm{D}$ culture condition is a potent pro-myogenic cue, that facilitates the formation of fully differentiated myotubes, which is in agreement with other reports (Carosio et al., 2013); 3D cell-cell contacts bypass inhibitory signals for muscle differentiation, such as culture in minimal, serum-free medium (Minotti et al., 1998; De Arcangelis et al., 2003), and promote the formation of a functionally active construct capable of contraction. From these results, we conclude that MAS is not necessary for muscle formation in 3D cultures. We do, however, confirm the results of our previous study (Perniconi et al., 2011), demonstrating that MAS is an excellent support for 3D myogenic cultures, both in vitro and in vivo (in the latter case, when orthotopically grafted). In addition, MAS is compatible with the differentiation toward the osteogenic lineage, obtained by BMP-2 treatment of the $\mathrm{C} 2 \mathrm{C} 12$ cell line, which thus demonstrates that MAS does not represent a signal that fully and irreversibly commits cells to a myogenic fate. In conclusion, MAS has scaffold properties insofar as it supports cell attachment, migration, survival and differentiation. Whether MAS is a good support for cells of non-muscle origin and whether it can be exploited in trans-species experiments, such as cultivating human cells in murine MAS, remains to be addressed. However, accumulating evidence suggests that acellular scaffolds of biological origin are multipurpose and may be exploited for cell culture and tissue engineering of different tissue types regardless of their origin (Badylak et al., 1998; Conconi et al., 2005; Wolf et al., 2012).

It is widely accepted that the niche supports stem cells and controls their self-renewal in vivo (Spradling et al., 2001) by modulating asymmetric cell division and ensuring stem cell renewal and the production of a number of committed daughter cells that is sufficient for tissue homeostasis and repair (Kuang et al., 2008). The notion of the niche appears to be closely linked to that of the stem cell; however, in addition to affecting stem cell renewal, the microenvironment also controls commitment and differentiation of daughter cells deriving from asymmetrically dividing stem cells (Zhang et al., 2009; Bhattacharyya et al., 2012). Intriguingly, the niche itself is not always indispensable for asymmetric division and stem cell renewal, as shown by the case of lymphocyte differentiation in the absence of a permanent niche (Chang and Reiner, 2008). Cell-intrinsic factors, such as DNA strand asymmetric division and segregation, play additional, important roles in determining the asymmetric fate of daughter cells (Shinin et al., 2006). A very recent report established a novel paradigm for stemcell maintenance according to which a dynamically heterogeneous cell population functions long term as a single stem-cell pool (Ritsma et al., 2014). Our findings suggest that this degree of plasticity might be extended to committed cells and be inherent to ECM components.

The notion of the microenvironment is of paramount importance when dealing with tissue engineered constructs aimed at regenerative medicine applications. Although some features of 
regeneration are shared by different tissues whereas others are tissue-specific, all those features are ultimately controlled by the tissue microenvironment. Understanding the mechanisms underlying tissue regeneration, particularly the choice between tissue restoration and reconstruction (two different strategies following tissue injury), is essential for regenerative medicine interventions (Coletti et al., 2013). The microenvironment (including the stem cell niche) is determined by three major components: the ECM, the cells and the local growth factors. In our work, we investigated whether MAS (which is basically composed of muscle ECM) is sufficient to recapitulate the effects of the muscle microenvironment on cell differentiation. We found that MAS displays features that are typical of a scaffold, though it is not strictly limited to muscle applications since it does not irreversibly commit cells to a myogenic fate. We conclude by saying that since MAS does not fully recapitulate muscle-specific microenvironment properties, it may be more plastic, and consequently easier to exploit, than has previously been believed.

\section{ACKNOWLEDGMENTS}

We gratefully thank Lewis Baker for reviewing the English in the manuscript and to Dr. Mathias Mericskay for the assistance with the renal capsule grafting technique. Funding of this work was provided by MERIT \#RBNE08HM7T, Fondazione San Raffaele, Ceglie Messapica to Laura Teodori. Additional financial support was provided by UPMC Emergence (2011-EME1115), AFM (2012-16117) and ANR (2013-J13R191) to Dario Coletti, as well as by PRIN 2009WBFZYM_001 and Sapienza C26A125ENW to Sergio Adamo. Part of the research funds and the postdoctoral fellowships for Barbara Perniconi and Paola Aulino were provided by Calabrodental in the context of a "PROMETEO Project-Progettazione e Sviluppo di piattaforme tecnologiche innovative ed ottimizzazione di PROcessi per applicazioni in MEdicina rigenerativa in ambito oromaxillofaciale, emaTologico, nEurologico e cardiOlogico" PON01_02834 granted by the Italian MIUR.

\section{REFERENCES}

Adler, B. J., Green, D. E., Pagnotti, G. M., Chan, M. E., and Rubin, C. T. (2014). High fat diet rapidly suppresses B lymphopoiesis by disrupting the supportive capacity of the bone marrow niche. PLoS ONE 9:e90639. doi: 10.1371/journal.pone.0090639

Badylak, S. F. (2007). The extracellular matrix as a biologic scaffold material. Biomaterials 28, 3587-3593. doi: 10.1016/j.biomaterials.2007.04.043

Badylak, S. F., Dearth, C. L., Rubin, J. P., Ambriosio, F., Boninger, M., Sicari, B. M., et al. (2013). "A Biologic scaffold approach to promote functional skeletal muscle in patients with volumetric muscle loss," in Termis-AM Conference: Celebrating 25 Years of Transformative Science and Engineeing (Atlanta, GA).

Badylak, S. F., Kropp, B., McPherson, T., Liang, H., and Snyder, P. W. (1998). Small intestinal submucosa: a rapidly resorbed bioscaffold for augmentation cystoplasty in a dog model. Tissue Eng. 4, 379-387. doi: 10.1089/ten.1998.4.379

Bhattacharyya, S., Kumar, A., and Lal Khanduja, K. (2012). The voyage of stem cell toward terminal differentiation: a brief overview. Acta Biochim. Biophys. Sin. (Shanghai). 44, 463-475. doi: 10.1093/abbs/gms027

Borschel, G. H., Dennis, R. G., and Kuzon, W. M. Jr. (2004). Contractile skeletal muscle tissue-engineered on an acellular scaffold. Plast Reconstr. Surg. 113, 595-602. discussion 603-594. doi: 10.1097/01.PRS.0000101064. $62289.2 \mathrm{~F}$

Carosio, S., Barberi, L., Rizzuto, E., Nicoletti, C., Del Prete, Z., and Musaro, A. (2013). Generation of $e X$ vivo-vascularized Muscle Engineered Tissue (X-MET). Sci. Rep. 3:1420. doi: 10.1038/srep01420
Chang, J. T., and Reiner, S. L. (2008). Asymmetric division and stem cell renewal without a permanent niche: lessons from lymphocytes. Cold Spring Harb. Symp. Quant. Biol. 73, 73-79. doi: 10.1101/sqb.2008.73.008

Coletti, D., Teodori, L., Lin, Z., Beranudin, J., and Adamo, S. (2013). Restoration versus reconstruction: cellular mechanisms of skin, nerve and muscle regeneration compared. Regen. Med. Res. 1:4. doi: 10.1186/2050-490X-1-4

Conconi, M. T., De Coppi, P., Bellini, S., Zara, G., Sabatti, M., Marzaro, M., et al. (2005). Homologous muscle acellular matrix seeded with autologous myoblasts as a tissue-engineering approach to abdominal wall-defect repair. Biomaterials 26, 2567-2574. doi: 10.1016/j.biomaterials.2004.07.035

Coquelin, L., Fialaire-Legendre, A., Roux, S., Poignard, A., Bierling, P., Hernigou, P., et al. (2012). In vivo and in vitro comparison of three different allografts vitalized with human mesenchymal stromal cells. Tissue Eng. Part A 18, 1921-1931. doi: 10.1089/ten.tea.2011.0645

Crapo, P. M., Gilbert, T. W., and Badylak, S. F. (2011). An overview of tissue and whole organ decellularization processes. Biomaterials 32, 3233-3243. doi: 10.1016/j.biomaterials.2011.01.057

Dahms, S. E., Piechota, H. J., Dahiya, R., Lue, T. F., and Tanagho, E. A. (1998). Composition and biomechanical properties of the bladder acellular matrix graft: comparative analysis in rat, pig and human. Br. J. Urol. 82, 411-419. doi: 10.1046/j.1464-410X.1998.00748.x

De Arcangelis, V., Coletti, D., Canato, M., Molinaro, M., Adamo, S., Reggiani, C., et al. (2005). Hypertrophy and transcriptional regulation induced in myogenic cell line L6-C5 by an increase of extracellular calcium. J. Cell. Physiol. 202, 787-795. doi: 10.1002/jcp.20174

De Arcangelis, V., Coletti, D., Conti, M., Lagarde, M., Molinaro, M., Adamo, S., et al. (2003). IGF-I-induced differentiation of L6 myogenic cells requires the activity of cAMP-phosphodiesterase. Mol. Biol. Cell 14, 1392-1404. doi: 10.1091/mbc.E02-03-0156

Faulk, D. M., Johnson, S. A., Zhang, L., and Badylak, S. F. (2013). Role of the extracellular matrix in whole organ engineering. J. Cell. Physiol. 229, 984-989. doi: $10.1002 /$ jcp. 24532

Friedrichs, M., Wirsdoerfer, F., Flohe, S. B., Schneider, S., Wuelling, M., and Vortkamp, A. (2011). BMP signaling balances proliferation and differentiation of muscle satellite cell descendants. BMC Cell Biol. 12:26. doi: 10.1186/14712121-12-26

Katagiri, T., Yamaguchi, A., Komaki, M., Abe, E., Takahashi, N., Ikeda, T., et al. (1994). Bone morphogenetic protein-2 converts the differentiation pathway of C2C12 myoblasts into the osteoblast lineage. J. Cell Biol. 127, 1755-1766. doi: 10.1083/jcb.127.6.1755

Kirkpatrick, C. J. (2014). Developing cellular systems in vitro to simulate regeneration. Tissue Eng. Part A. 20, 1355-1357. doi: 10.1089/ten.tea.2014.0002

Klumpp, D., Horch, R. E., Kneser, U., and Beier, J. P. (2010). Engineering skeletal muscle tissue-new perspectives in vitro and in vivo. J. Cell. Mol. Med. 14, 2622-2629. doi: 10.1111/j.1582-4934.2010.01183.x

Kuang, S., Gillespie, M. A., and Rudnicki, M. A. (2008). Niche regulation of muscle satellite cell self-renewal and differentiation. Cell Stem Cell 2, 22-31. doi: 10.1016/j.stem.2007.12.012

Langer, R., and Vacanti, J. P. (1993). Tissue engineering. Science 260, 920-926. doi: 10.1126/science.8493529

Leotot, J., Coquelin, L., Bodivit, G., Bierling, P., Hernigou, P., Rouard, H., et al. (2013). Platelet lysate coating on scaffolds directly and indirectly enhances cell migration, improving bone and blood vessel formation. Acta Biomater. 9, 6630-6640. doi: 10.1016/j.actbio.2013.02.003

Macchiarini, P., Jungebluth, P., Go, T., Asnaghi, M. A., Rees, L. E., Cogan, T. A., et al. (2008). Clinical transplantation of a tissue-engineered airway. Lancet 372 , 2023-2030. doi: 10.1016/S0140-6736(08)61598-6

Mericskay, M., Kitajewski, J., and Sassoon, D. (2004). Wnt5a is required for proper epithelial-mesenchymal interactions in the uterus. Development 131, 2061-2072. doi: 10.1242/dev.01090

Meyer, T., Chodnewska, I., Czub, S., Hamelmann, W., Beutner, U., Otto, C., et al. (1998). Extracellular matrix proteins in the porcine pancreas: a structural analysis for directed pancreatic islet isolation. Transplant. Proc. 30, 354. doi: 10.1016/S0041-1345(97)01302-X

Minotti, S., Scicchitano, B. M., Nervi, C., Scarpa, S., Lucarelli, M., Molinaro, M., et al. (1998). Vasopressin and insulin-like growth factors synergistically induce myogenesis in serum-free medium. Cell Growth Differ. 9, 155-163.

Musaro, A., Giacinti, C., Pelosi, L., Dobrowolny, G., Barberi, L., Nardis, C., et al. (2007). Stem cell-mediated muscle regeneration and repair in aging and 
neuromuscular diseases. Eur. J. Histochem. 51(Suppl. 1), 35-43. doi: 10.4081/ 1403

Naro, F., De Arcangelis, V., Coletti, D., Molinaro, M., Zani, B., Vassanelli, S., et al. (2003). Increase in cytosolic $\mathrm{Ca}^{2+}$ induced by elevation of extracellular $\mathrm{Ca}^{2+}$ in skeletal myogenic cells. Am. J. Physiol. Cell Physiol. 284, C969-C976. doi: 10.1152/ajpcell.00237.2002

Ott, H. C., Matthiesen, T. S., Goh, S. K., Black, L. D., Kren, S. M., Netoff, T. I., et al. (2008). Perfusion-decellularized matrix: using nature's platform to engineer a bioartificial heart. Nat. Med. 14, 213-221. doi: 10.1038/nm1684

Perniconi, B., and Coletti, D. (2014). Skeletal muscle tissue engineering: best bet or black beast? Front. Physiol. 5:255. doi: 10.3389/fphys.2014.00255

Perniconi, B., Costa, A., Aulino, P., Teodori, L., Adamo, S., and Coletti, D. (2011). The pro-myogenic environment provided by whole organ scale acellular scaffolds from skeletal muscle. Biomaterials 32, 7870-7882. doi: 10.1016/j. biomaterials.2011.07.016

Ritsma, L., Ellenbroek, S. I., Zomer, A., Snippert, H. J., De Sauvage, F. J., Simons, B. D., et al. (2014). Intestinal crypt homeostasis revealed at single-stem-cell level by in vivo live imaging. Nature 507, 362-365. doi: 10.1038/nature12972

Rochlin, K., Yu, S., Roy, S., and Baylies, M. K. (2010). Myoblast fusion: when it takes more to make one. Dev. Biol. 341, 66-83. doi: 10.1016/j.ydbio.2009.10.024

Shinin, V., Gayraud-Morel, B., Gomes, D., and Tajbakhsh, S. (2006). Asymmetric division and cosegregation of template DNA strands in adult muscle satellite cells. Nat. Cell Biol. 8, 677-687. doi: 10.1038/ncb1425

Sivan, U., Jayakumar, K., and Krishnan, L. K. (2014). Matrix-directed differentiation of human adipose-derived mesenchymal stem cells to dermal-like fibroblasts that produce extracellular matrix. J. Tissue Eng. Regen. Med. doi: 10.1002/term.1865. [Epub ahead of print].

Spradling, A., Drummond-Barbosa, D., and Kai, T. (2001). Stem cells find their niche. Nature 414, 98-104. doi: 10.1038/35102160

Teodori, L., Costa, A., Marzio, R., Perniconi, B., Coletti, D., Adamo, S., et al. (2014). Native extracellular matrix: a new scaffolding platform for repair of damaged muscle. Front. Physiol. 5:218. doi: 10.3389/fphys.2014.00218

Wang, S., Guo, L., Dong, L., Guo, L., Li, S., Zhang, J., et al. (2010). TGF-betal signal pathway may contribute to rhabdomyosarcoma development by inhibiting differentiation. Cancer Sci. 101, 1108-1116. doi: 10.1111/j.1349-7006.2010. 01512.x
Whitney, G. A., Mera, H., Weidenbecher, M., Awadallah, A., Mansour, J. M., and Dennis, J. E. (2012). Methods for producing scaffold-free engineered cartilage sheets from auricular and articular chondrocyte cell sources and attachment to porous tantalum. Biores. Open Access 1, 157-165. doi: 10.1089/biores. 2012.0231

Wolf, M. T., Daly, K. A., Reing, J. E., and Badylak, S. F. (2012). Biologic scaffold composed of skeletal muscle extracellular matrix. Biomaterials 33, 2916-2925. doi: 10.1016/j.biomaterials.2011.12.055

Yin, H., Price, F., and Rudnicki, M. A. (2013). Satellite cells and the muscle stem cell niche. Physiol. Rev. 93, 23-67. doi: 10.1152/physrev.00043.2011

Zhang, Y. V., Cheong, J., Ciapurin, N., McDermitt, D. J., and Tumbar, T. (2009). Distinct self-renewal and differentiation phases in the niche of infrequently dividing hair follicle stem cells. Cell Stem Cell 5, 267-278. doi: 10.1016/j.stem.2009.06.004

Conflict of Interest Statement: The authors declare that the research was conducted in the absence of any commercial or financial relationships that could be construed as a potential conflict of interest.

Received: 02 April 2014; accepted: 30 August 2014; published online: 26 September 2014.

Citation: Perniconi B, Coletti D, Aulino P, Costa A, Aprile P, Santacroce L, Chiaravalloti E, Coquelin L, Chevallier N, Teodori L, Adamo S, Marrelli $M$ and Tatullo M (2014) Muscle acellular scaffold as a biomaterial: effects on C2C12 cell differentiation and interaction with the murine host environment. Front. Physiol. 5:354. doi: $10.3389 /$ fphys.2014.00354

This article was submitted to Striated Muscle Physiology, a section of the journal Frontiers in Physiology.

Copyright (c) 2014 Perniconi, Coletti, Aulino, Costa, Aprile, Santacroce, Chiaravalloti, Coquelin, Chevallier, Teodori, Adamo, Marrelli and Tatullo. This is an open-access article distributed under the terms of the Creative Commons Attribution License (CC BY). The use, distribution or reproduction in other forums is permitted, provided the original author(s) or licensor are credited and that the original publication in this journal is cited, in accordance with accepted academic practice. No use, distribution or reproduction is permitted which does not comply with these terms. 